\title{
“An Invented Archive”: The Disability History Museum
}

The SePtember 2006 issue of the Chronicle of Higher Education included a special supplement on "Diversity in Academic Careers." It focused primarily on race and ethnicity; sexual preference received minimal attention. No references were made, however, to disability, although disabled Americans can be said to comprise the largest single "minority group" in the United States. Consider the following: according to the 2000 U.S. Census, 49.7 million people, representing 19.3 percent of the 257.2 million people aged five and older in the civilian noninstitutionalized population (or almost one in five U.S. residents), lives with some type of long-lasting condition or disability. During the last thirty years, people with disabilities, inside and outside institutions, have come under the protection of civil rights guarantees of access and inclusion through a complex legal process. But as the Civil Rights Movement taught us, laws alone do not change attitudes-awareness must be raised and assumptions challenged.

\section{Including Disability within Diversity: A Rationale}

Disability is often described as a matter involving impairment to a physiological or neurological/psychological process requiring medical treatment. When such impairment limits one's ability to conduct typical daily living functions independently, the condition can create a "disability." But the medical aspects are just one component of a life lived with a disability. Beyond the medical sphere, many disabled individuals find themselves in social spaces where they share the same dilemmas faced by those who are considered to be "different" as a consequence of race, sexual preference, ethnicity, or religious belief. Moreover, as a category of human experience, disability is included in every one of these diverse populations.

The Education for All Handicapped Children Act of 1975, the Vocational Rehabilitation Act of 1973 (known as "504" in community advocacy shorthand), and the ADA - the Americans with Disabilities Act of 1990, guaranteed disabled people inclusion in and access to all aspects of U.S. social life as a matter of federal civil 
rights. But "access" in this context means more than the built environment, more than bricks and mortar, more than ramps and bathrooms. It includes bureaucratic systems, communication practices, universal design in education (buildings and pedagogy), and universal design of consumer goods. These efforts over time will reorganize human experiences with consequence for the whole population, disabled or not - a process well underway not just in the U.S., but around the globe. The 2006 United Nations Convention on the Rights of Persons with Disabilities will be a pioneering and forceful influence in this process.

This cultural restructuring is one of the most important milestones in 20th century U.S. civil and human rights history. Yet most Americans do not have an inkling as to what led to special education services or how curb cuts and accessible bathrooms came to be. People with disabilities engage in all facets of our national life and are now seen at the grocery store, at school, in college, in the workplace, or at the movies. Anyone over the age of thirty can remember when this was simply not the case, but few people can describe how life lived with a disability today (across the life span) came to acquire its contemporary shape.

Disability history is rich, dramatic, and relevant to all humankind. Regardless of race, class, or gender, anyone at any time in his or her life can become disabled. Almost everyone knows someone with a disability, and this has always been the case. Despite the significant changes that have radically expanded the cultural opportunities available to people with disabilities, traditional stereotypes continue to have currency, as do the limited expectations that go with them. Such attitudes affect the nature of the work that people with disabilities are able to secure, the places where they can live, their social experiences, and their identity as young, middle aged, or older citizens.

The Disability History Museum (DHM) ${ }^{1}$ was founded in 2000 with the aim of creating tools that could help anyone-with or without a disability-develop a better sense of how vital to our common life the records and historical experiences of people with disabilities have been. And though, as its founder, in some settings I still get asked, "what is disability history," slow but steady changes in several arenas make answering this question easier.

\section{Missing Pieces}

The field called "Disability History" was recently added to the official list of academic specialties that comprise the areas of scholarship addressed by the American History Association (AHA). Writing in the AHA newsletter, Linda Kerber, immediate past president of the AHA, declared that this new realm of scholarship

1. See www.disabilitymuseum.org. 
raise[s] challenging questions: What hidden assumptions have we made about what counts as an interesting subject of study and analysis? ...What hidden assumptions have we made about what is needed — besides smartsto be a historian? What do we count as competence? ... All activists are hungry for their history ... So it is with disability history. In turn, the new disability history will enable all of us to understand not just a social movement, but all history better. ${ }^{2}$

But perhaps a statement by Simi Linton, a longtime disability rights activist, suggests more directly the different directions research and thinking about disability history takes its students. She notes that disability as a subject of analysis "deepens the understanding of gender and sexuality, individualism and equality, minority group definitions, autonomy, wholeness, independence, dependence, health, physical appearance, aesthetics, the integrity of the body, community, and notions of progress and perfection." ${ }^{3}$

The Disability History Museum's "virtual headquarters" is in a barn at my home in Massachusetts. Its three sectors-Library, Education, and Museum-were conceived as a means to promote understanding by recovering, chronicling, and interpreting stories about the historical experience of people with disabilities. Our goal is to place this history in relationship to traditional themes in American Studies, such as states versus federal rights, matters of voice and representation, issues of class, urbanization, aesthetics, economic and environmental change. This is an online project: we have no plans to build a brick-and-mortar museum, though we regularly partner with institutions that are more typically situated. The DHM is sponsored by Straight Ahead Pictures, Inc., a small nonprofit organization that creates innovative media projects and educational forums to foster community dialog about contemporary social issues, using archival materials and oral history.

I will focus on two tenets that the DHM was created to support: 1) that disability history includes far more than medical history-it is an interdisciplinary subject that reveals much about how our society has organized itself; and 2) that as individuals and as a society we have a woeful lack of common knowledge and vocabulary about how to describe the historical changes experienced by people with disabilities and their family-social networks.

2. Linda K. Kerber, "Enabling History," Perspectives: Newsletter of the American Historical Association, 44:8 (2006).

3. Simi Linton, "The Disabilities Study Project: Broadening the Parameters of Diversity," in Elaine Makas and Lynn Schlesinger, eds., End Results and Starting Points: Expanding the Field of Disability Studies (Boston: Society for Disability Studies, 1996), 323-25. 


\section{Getting Started}

The process behind "inventing an archive" is perhaps a useful starting point. Before the creation of the DHM, I worked for many years with a small staff (never more than four part-timers) making documentaries for radio, television/film, and the Internet about the cultural history of the body with an emphasis on the disability experience. We also focused on education efforts in media and visual literacy and history. Each project undertaken required significant financial development-a subject beyond the scope of the present article. We did our work using various formats, including extensive interviews and oral histories, researching factual and newsreel footage and old radio programs, and much traditional print and book study. But by the mid 1990s, independent documentary producers, like all media professionals, experienced upheavals in how they worked as a consequence of the Internet's growth, the fracturing of the television audience as niche-market cable channels multiplied, and the reduction of public and private funding for high-quality documentary productions. Research processes were also profoundly changed by the Web. And what is the good news? Novel acquisition, distribution, and dissemination possibilities developed. No one in the public radio and television world knew then where these new conditions and possibilities would lead, but the Corporation for Public Broadcasting (CPB) began investing in online, Web-based production ideas, at PBS and NPR stations and with a few independent producers like me.

At that time, I had an overflow of research material from a production funded primarily by the CPB with support from the AT\&T Corporation for a four-hour radio NPR series called Beyond Affliction: The Disability History Project. ${ }^{4}$ Using these materials, and with the help of CPB funds, I initiated an online companion to the series that eventually evolved into what Roy Rosenzweig, Head of the Center on History and New Media at George Mason University, has termed an "invented archive." 5 Rather than leave all the outtakes (sections of film or recordings not used in a final film or radio production) on the cutting room floor, we built a very deep Web site (using HTML) that included hundreds of Web-paged versions of the primary-source texts, images, and audio clips acquired for Beyond Affliction during the research period. Late one night, as we neared our broadcast deadline, a software engineer, Erik Haugsjaa (then a doctoral student in the Computer Science Department at the University of Massachusetts, Amherst), helping to build the backend

4. Beyond Affliction: The Disability History Project. Producers: Laurie Block with Jay Allison. Funding provided by the Corporation for Public Broadcasting, AT\&T Corporation, The New Prospect, The Milbank and the MacArthur Foundations (1998); winner 1999 Robert Kennedy Radio Journalism Award for Social Justice.

5. Michael O’Malley and Roy Rosenzweig, "Brave New World or Blind Alley? American History on the World Wide Web," Journal of American History, 84:1 (1997): 132-55. 
of that site, turned to me and asked if I knew about databases and XML. That was long ago-1998. I told him all my research was in Filemaker, and he suggested we talk later, which we did in great detail.

For about six months in 1999, I set out to learn all that I could about Web design, surveying several hundred sites created by museums, artists, libraries, teachers, PBS, and corporations (from whose deeply built sites I found I learned the most). I attended professional development workshops and study sessions related to developing Web sites at conferences sponsored by the American Association of Museums. I kept notes and read several books on the subject. ${ }^{6}$ Unlike the World Wide Web of today, back then one could really feel as if one had seen a great deal of the Web. Within a few years, the second iteration of the Beyond Affliction companion Web site yielded up the Disability History Museum.

As noted, the DHM was conceived to have three sectors, each with a somewhat different audience and purpose. One is the Library; a second, Education, provides educational materials using the library's primary resources but adding content to them as well as lessons and interpretive background materials. The site's third sector, Museum (which is not yet completed), will use all these materials but add a stand-alone interpretive layer of content for exhibitions. Only the library is currently "open" to the public. However, the education and museum sectors" "backends" have been engineered. Educational curriculum materials have been created, piloted, and evaluated but will remain password protected for another six months. I am pleased to report here that recent new funding from the National Endowment for the Humanities will enable us to open the site's education sector to the public. This prospect makes what has felt to be an eternally unfilled promise - that part of the Web site labeled as "Coming Soon, Under Construction" - a reality.

The barn from which the project currently operates is a mid-nineteenth century structure, with chestnut beams and a slate roof, and an office built into the old hayloft. But the DHM is "built" upon a custom mix of SQL, PHP, XML, JavaScript, CSS, CGI, HTML, and JPEGs with TIFF masters on CDs, and file cabinets of photocopied materials as hard-copy backups. For the most part, we do not own the artifacts in the library collections, except for those materials generated, purchased, or "found" for use in a documentary radio or film production-including audio and video interviews, new shooting, ephemera, and print images of all varieties.

6. I found the best book from that period to be Jessica R. Burdman, Collaborative Web Development: Strategies and Best Practices for Web Teams (Reading, MA: Addison Wesley, 1999). 


\section{A Theme Library's Collection Development Strategy}

The foundation of the entire DHM Web site is its library. Currently we have two types of digital artifacts available - documents and visual still images - but an audiovisual collection will soon be added. From the beginning of the project, we have concentrated on building our collections for the purpose of using them as "content" for the site's museum and education programs. To build our library collection, we "borrow" artifacts (with permission) from existing public and private archives and convert them into XML documents or scanned images. We offer each item in the library in an unabridged format. We decided to use XML to number each text by paragraph. This allows for easy citation, and perhaps more importantly for our purposes, it facilitates our ability to abridge the texts for use in other sectors of the site.

Our collecting policy was developed with specific aims and the help of our academic board of advisors. Our initial goals included creating easy access to an array of materials that would help point researchers, reference librarians, the general public, educators and students, curators of museums and archivists, indeed professionals of many kinds, as well as advocates and community activists, toward recognizing the rich array of sources that reflect the varieties and patterns of records about disability experiences in different chronological periods nationally. This meant we needed to identify and include a variety of genre (i.e., categorical or "kind of") records, artifacts that may not be rare or unusual but that reflect much about a period or specific experience of an entire population - the annual reports of residential schools and asylums, "patient" newsletters, parental advocacy records, fundraising materials for assistive technology or support for various groups. The one genre topic we chose not to focus upon was the medical aspects of physiological conditions. Those records are made widely available by many medical libraries and museums, although we sometimes use medical history texts when they reflect the cultural history of people with disabilities. We do, however, make available unique items that were exceptions to mainstream disability experiences, as these can present stories of resistance to dominant discourses. Our geographic focus is on disability experiences within the United States, but our collection cuts across disability categories. This means we acquire material about the people with cognitive or psychiatric disabilities, mobility impairments, sensory impairments, visible or invisible conditions, and we look for ways to collect materials about disability across the life span.

A second but equally important priority was creating library collections that could serve DHM's education and museum needs. This required us to establish collection phases coordinating the acquisition of content for inclusion in curriculum modules that modeled how disability history integrates within central themes in typical American History and American Studies course work. Most of this effort will 
become visible to the public when our education sector opens, but it has affected how we have phased our collection development. For example, as one of our first modules will deal with Lunacy Reform in the 19th century, we focused on the supporters and the opponents of the American activist Dorothea Dix's efforts to win federal funding for persons with mental illness.

A third aspect of building our collection had to do with our sponsoring organization's size. To build a virtual library and museum without formal academic or institutional backing meant we necessarily had to focus our energy not only on content development but on a dynamic backend delivery system that would 1) automate many processes, 2) be readily "morphable" with changes to software, and 3) be capable of scaling up over time. Those are the concerns of any good digital library or museum project, but our financial development capacity and small infrastructure made these issues even more urgent.

As we added primary source content to our library, we did not (and cannot) ever aim to be comprehensive in approach. We strongly felt it was not necessary to provide every annual report of a school for the "feeble minded" in each state. But we thought scholars would benefit if we could offer a sampling of such records across time and geography. We began this process with a run of the Annual Reports of the New York State Asylum for Idiots near Syracuse (an institution that long persisted under other names). The reports were written by Dr. Hervey B. Wilbur, the first superintendent. This fall we will be adding a rich sample of annual reports from the early years of the New England Institution for the Education of the Blind written by the famed educator, Samuel Gridley Howe, and several from the late 19th century written by the director, Michael Anagnos, when the school was known as the Perkins Institute for the Blind.

Informative as they often are, an institution's annual reports do not offer the perspective of a person with a disability. For that we chose other types of sampling as part of our first phase of library collection development, and a good example of this is the digitization of so-called "patient newsletters." The Opal is one of my favorites. It was a 19th-century patient-published and -edited newsletter produced at the New York State Asylum for the Insane in Utica. The writers are remarkably erudite, and their perspective likely stunned and surprised readers then as they do today, if for different reasons. This newsletter offers a lively if sometimes difficult to decode - is this parody or reportage? - insider's view of life lived in an insane asylum in the period 1850-1860. Until we digitized a sample of these records, this resource was not readily known or accessible. Only a few libraries had the publication. But The Opal and other newsletters like it serve as rich if complex records of those who lived in public asylums for the so-called insane. 
Similarly, The Polio Chronicles are found in very few locations. This newsletter-magazine was published between 1931 and 1934 by the National Patients Committee of the Warm Springs Institute for Rehabilitation in Warm Springs, Georgia, and it offers an extraordinary, groundbreaking, independent-living grassroots perspective. This "rag" (as it called itself) flourished for a very short time as part of the Warm Springs Foundation's efforts to build the Roosevelt Institute for Rehabilitation anew from its former existence as the Merriweather Inn, a mineral springs spa. Franklin D. Roosevelt had visited the Inn in an attempt to rehabilitate his leg muscles, which were greatly weakened by the polio he had contracted in 1921, and he was so impressed with his experiences there that in 1926 he spent a major portion of his personal fortune to buy the resort and turn it into a facility for the treatment of polio. Although The Polio Chronicles would be followed by other Warm Spring patient-written newsletters, these early articles are especially important. They illuminate how Roosevelt and his peers saw themselves and their circumstances in the era just prior to Roosevelt's presidency, and before the National Infantile Paralysis Foundations (or March of Dimes) publicity machine came into being. These writers talk about their concerns and problems in social terms; they describe the discrimination they encounter and use the language of "equal opportunity" in their charter. Commonly, they see the problems they face as disabled individuals as matters of social policy and cultural attitudes. Notably, the only time they seem to become sentimental is when they discuss fundraising. As with The Opal, putting this newsletter online makes it available to a much larger audience. Like newsletters written by patients inside asylums, The Polio Chronicles is an early example of a genre, the rehab-center or diagnosis group community newsletter articulating grassroots concerns.

The DHM's collections come from many public and private archives all over the country. We provide in our online catalogue the artifact's source-provenance information. Also offered on this catalog page is an excerpt of the text or a thumbnail of the image, a "tease" if you will, to entice and familiarize users with the item's content. The thumbnails are clearly marked with an owner's identification, if so requested, and always are made available in low-resolution mode so that users with an interest in publishing them must contact the owner of the actual artifacts.

Our collection strategy was developed with the help of the project's academic and community representative advisors. All of us were aware of the paucity of models for telling public history disability stories. Those that do exist tend to describe progress toward medical cures or tell "struggle and triumph" tales-how I fought discrimination and won the battle, or how I fought this or that disease. These are important parts of the record, but where are the stories of those who have simply lived on with a chronic condition? How have the experiences of ordinary people with dis- 
abilities been shaped, and how have they in turn shaped the lives of our communities? Like gender and race, disability is a core aspect of identity. It is also a significant interdisciplinary category, and one that is useful for larger historical analysis.

Creating tools for browsing and cataloging our collection posed some complex problems. In the site-building planning period, we defined a different audience for each of our sectors, but building search tools for the library required thinking about how these audiences might overlap and how they might find the materials we had to offer. The exercise of defining the end users for all of our site sectors generated a wide-ranging list: researchers in academic fields in the humanities and social sciences, both students and educators; professionals, such as hospital administrators, preparing a speech about their institution; a school superintendent or special education director doing research for a talk to parents or to legislators; physical therapists curious about the history of their profession; circus and sideshow collectors; and people of all ages with disabilities. The education sector would target high school and higher education users; the library would draw a general public. The one group not mentioned on our original list was genealogists, and we hear from them all the time when they track relatives whose last trace is the entrance of a public hospital. But developing search tools for the history of disability that had to serve everyone from junior high students to academic professionals doing doctoral or book research required careful thinking.

We created a controlled vocabulary of keywords and used Library of Congress subject terms as a guide, but sometimes we invented our own categories, with input from our board of advisors. The problem we most often faced was how names of conditions and names for categories of people's experience constantly changed. Manifestations of disabling conditions, congenital or acquired, are called by many names. But a long historical view makes clear that diagnostic labels prevailing in one period often change or entirely disappear in another. The philosopher Ian Hacking dubs this taxonomical process and its consequences "making up people."7 $\mathrm{He}$ describes a "looping effect" in which the cultural response to categorizing generates social practices that organize various human experiences, which in turn shapes the development of our cultural rhetoric, ideas, and convictions; our bureaucratic structures and technologies; and our local ordinances and national legislation, proposed or implemented. Hacking suggests these processes have a spiral shape: ideas and people do not eternally return to their former places and then pass through the same gates.

Modern diagnostic labels such as Autism, Down syndrome, dyslexia, or even vaguer terms such as cerebral palsy were not in use in the 19th or early 20th centuries. And today, different groups within a population might see themselves as having signifi- 
cant differences from one another, as happens when terms such as "Deaf," "hard of hearing," "visually impaired," "legally blind," "blind," or " physically challenged" are used. These are time-bound categories, and in older records do not necessarily mean just what they mean today or what they will mean in the future. Even the buildings or bureaucratic government departments that serve people with disabilities are known to change their names every fifteen years or so, and state archives' online catalogs pose many terminological problems for ordinary users. So we struggled with our advisors to decide how to cluster general categories for browsing our collections. We wanted large search terms that would yield interesting results, reflect recent scholarship, and meet the concerns of people with disabilities themselves. We needed our keywords to be useful for scholarship but also to be appropriate for seventh graders and genealogists working well outside the bounds of medical or academic jargon.

To address these needs, we built in high-level general terms such as "sensory" (deaf, blind), "psychiatric," and "cognitive" disability. But we also coded our artifacts using historical variants for terms when appropriate. DHM library visitors can search for records associated with "feeble-mindedness" or "almshouses" or "asylums," but when they do they will get only those items that use the term as part of the common vernacular of a period. The almshouse of 1900 is a homeless shelter today, different in some ways, quite similar in others. To help visitors find our library's materials, we include in the metadata for each artifact's "page" all the keywords we assign to each library record we create, and then some related to the Web site as a whole. It works. Some 4,000-7,000 visitors come through our library weekly, the numbers falling lower in the summer.

\section{Crossing a Threshold: In Education, XML Applied}

It is in DHM's education sector that the XML strategy for artifacts begins to serve distinctly new purposes. All our library's holdings are tagged in the many tidy ways made possible through XML, and as a consequence they are efficiently abridged for teaching purposes. For example, the May 3, 1854, Presidential veto by Franklin Pierce of Dorothea Dix’s bill for support of the mentally ill is a long document found in our library. High school teachers will not use the whole text in their class, though higher education faculty might. The argument made by Pierce is powerful and ideal for introducing issues about social welfare policy and state versus federal responsibilities. In our education sector, we have created an abridged document for high school educators and their students, and it is simply a matter of plugging into an interface the selected paragraphs' number tags. We also add to each document an introduction and annotations, both of which help to contextualize the artifact for use by students. This context-adding process is much like historical publishing, and quite labor-intensive. But the work pays off in the teaching modules that help educators include disability history in survey course work. 
Furthermore, once generated, these introductions and annotations in the education sector and several other components of our education curriculum modules are, like the library artifacts themselves, "elements" readily exportable or importable to the museum sector of the site, to be worked into exhibitions or timelines. The foundation for all this work is the library, whose digital collections are the core content that the entire edifice depends upon. But it is a not-visible-to-thegeneral-public dynamic administrative interface that automates the process of importing and exporting "elements," abridging texts, or putting keywords into the metadata.

\section{Next Steps}

The next phase of building the DHM is connected to Straight Ahead Pictures' production of a television biographical documentary about Helen Keller, called Becoming Helen Keller. Our goal in both the education and museum sectors of the Web site is similar to those of the film: to place Keller's life and legacy into a larger historical context. The primary source artifacts we include in the library and the education sector curriculum materials are to be developed in conjunction with our institutional partners, Keene State College and the Hampshire Education Collaborative. They will explore themes of media celebrity and disability, the history of Keller's involvement in social welfare and human rights efforts for the disabled, as well as problems of gender, class, and disability in both her and Anne Sullivan's education and employment opportunities.

Since the Disability History Museum's initial inception, most of our technological design choices have held up very well. Our graphic presentation needs redesigning, and a few new tools will be added. We also feel the impact of new developments like YouTube, RSS, and the ever larger numbers of out of copyright books and articles available though Google Book Search or in subscription-based collections of historical newspaper and periodical databases. To keep going and growing, DHM needs to develop its peopled infrastructure. Our advisory committees help with the development efforts required to generate sufficient operating cash flow. The human labor requirements to make a project like this one sustainable are-simply put—difficult to support, and that is true whether one operates within the constructs of a small or large institution.

\section{Conclusion}

Our recent funding allows us to add materials about schools related to the blind, additional materials about the deaf (including debates about oralist education methods), and introduce other subjects related to disability. It will help us to make the 
representation of materials we offer more responsive to issues of race and broad national geography. It will also allow us to make available more materials concerning the history of cognitive and child development, as well as language acquisition. In our new phase of collecting and developing education materials, we will be focusing on a few key 20th-century disability policy debates, including workers' compensation, vocational rehabilitation, social security, and veterans' benefits. And, finally, we will assemble records that help users look at how both service and grassroots organizations of and for the blind and deaf worked in the first half of the 20th century.

Though there is no physical building to which we can send the people who write asking to visit the DHM, we do receive significant amounts of e-mail from our visitors. We also monitor their traffic inside the site very closely. Many people have found us, although no formal public promotion campaign has ever been conducted on the site's behalf. Most of the e-mail is from graduate student researchers, museum professionals, and genealogists. Ten percent of the traffic is international.

We monitor the keywords our visitors use, including those they tried that did not yield any results, and how long they remain on our site. The length of their visits surprised us: often, we have about 150-200 visitors weekly who spend from twenty minutes to two hours inside our virtual walls. We know who comes back a second time and are able to discount the people who may have left their browser window open, or who seem to be napping, as these visitors reveal themselves to be "stuck" on the same page for more than two hours at a time. As mentioned, when the project began, we developed a list of audience users for the library. This list proved remarkably accurate, and we hear via e-mail regularly from higher education and high school students doing various kinds of research, museum curators, and documentary film makers. We also assess our visitors by the e-mail they send us: we have had mail from veterans' hospital administrators working on anniversary or conference speeches and from people doing research or advocacy work in their own professions - including practicing and retired psychiatrists, lawyers, and physical therapists - all of whom are interested in specific topics on which we have material. We hear from online auction buyers and sellers, retired doctors and nurses, people with disabilities, their family members, their advocates, and genealogists.

Sometimes our visitors have brought us valuable new data about the records we have posted. My favorite example concerns Mabel Starret, who in the 1930s edited the letters column for children, called "Round Robin," for the Society for Crippled Children's magazine, Crippled Child. ${ }^{8}$ Her advice to the young in orthopedic hospitals, living at home, or attending special schools was consistently and

8. National Society for Crippled Children of the United States of America, The Crippled Child (Lorain, $\mathrm{OH}, 1923-1958)$. 
remarkably cogent and frank. Using their own words, she described their woes, their hopes, and their discoveries about life lived with various physical conditions. The language is sometimes sentimental and sometimes practical — how to do various daily living tasks more easily. Often it is about how it feels to be discriminated against. Her nephew, a genealogist, found her on our site, much to his surprise. $\mathrm{He}$ wrote to let us know where she had lived, and that she had an orthopedic condition herself. He also told us that she saw herself as an advocate, and lived a long and productive life as a citizen of her community in Illinois. Starret is one of our heroes at the DHM. It would have been quite difficult to follow up on her biography without this visitor's help.

When the DHM's education sector opens to the public, I believe it will be the most visited part of the site and will be readily utilized by students and faculty, from both secondary and higher education. It will open with a modest set of teaching tools, but we will continuously add to them.

Our efforts are not dissimilar to those humanities-based teaching sites that can be found at the University of Virginia, ${ }^{9}$ George Mason University, ${ }^{10}$ the Maine Memory Network, ${ }^{11}$ or the American Centuries sites at the Pocumtuck Valley Memorial Association, ${ }^{12}$ but our theme-based disability history content is novel. We are different. And the small infrastructure supporting the project up here on the second floor of this former livery stable makes the whole idea of 4,000-7,000 weekly virtual visitors traveling through seem almost dreamlike.

What will happen when there is a national broadcast of a television documentary about Keller and related (solid but virtual) education materials available in all the site's different sectors? Will we have a sufficient operating budget to manage the traffic that will follow this new phase? It could be a virtual barrel ride over a metaphorical Niagara Falls. We hope that by then we will be ready.

When I started this project, I had no idea of the scale of its ambitions, nor what the volume of work involved in creating a virtual library and museum would be. I could at that time never have predicted the abundance of resources that Google Book Search and Project Gutenberg generate each day, or the appearance of sites like "LibraryThing" that harness and share user-generated content. While the size of an operating budget sufficient for the steady functioning of an online operation like the DHM may be small compared to those of traditional museums and

9. See http://lib.virginia.edu/digital/ .

10. See http://chnm.gmu.edu/index.php.

11. See www.mainememory.net/.

12. See http://memorialhall.mass.edu/home.html. 
libraries, our actual budget is even smaller. It makes me realize that it is wise to be careful about what we dream about and wish for, but how all-important it is that we- and others like us - continue always to do so.

But let me close by describing a different type of dream, one that has to do with identifying those subjects that must be documented if we are to develop humanities perspectives about disability history. There are gaping holes in the historical record concerning the experiences of people with disabilities, and I would like to suggest some questions for consideration that might help readers of this article with personal or institutional strategic collection planning in this area. What materials might assist with documenting what it was like to be either a parent sending a child off to a residential school, or the student attending such an institution, in the 1930 s to the 1970s? What records relate the experiences of disability pioneers who provided the opportunity for a disabled child to attend public schools in the $1960 \mathrm{~s}$ and 1970s? Where is the documentary evidence that tells what happened to people who left institutions for the mentally ill and the retarded and moved back into the community, successfully or otherwise? Are there journals, diaries, or letters that help illuminate the experiences of disabled people employed in the WWII defense industry or those of conscientious objectors from the same era who were sent to work in institutions for disabled persons? What other materials offer opportunities to flesh out the lives and activities of individuals who lobbied for or benefited from new architectural-access codes, or for standards in the hearing-aid industry?

In general, disability advocacy and leadership has been a profoundly decentralized process, and the collection of materials related to them even more so. While every local community has had its own advocates and leaders, precious little of this localized legacy has been saved or preserved as the important historical records they are. But there are movements to more thoroughly and consciously fill in with evidence such "documentary holes." For instance, the Bancroft Library at the University of California, Berkeley, is collecting oral histories and papers from many national and local leaders in the disability rights and independent living movements from the 1960s onward and providing Internet access to this primary source material. Yet there are numerous other areas that could bear strategic documentation; the questions in the previous paragraph only begin my own list of "holes," suggesting possible directions for collection development. As we approach the 20th anniversary of the Americans with Disabilities Act in 2010, it seems a good time for curators, librarians, archivists, and other professionals working with special collections to begin thinking about acquiring and describing collections with an eye toward disability themes not previously considered of significant historical value. Accepting and understanding diversity as encompassing the breadth of subject material that it does, opens doors to increased knowledge and understanding of ourselves as well as those around us. 


\section{SWANN S}

AUTOGRAPHS • BOOKS/MANUSCRIPTS • MAPS/ATLASES PHOTOGRAPHS • POSTERS • WORKS OF ART ON PAPER

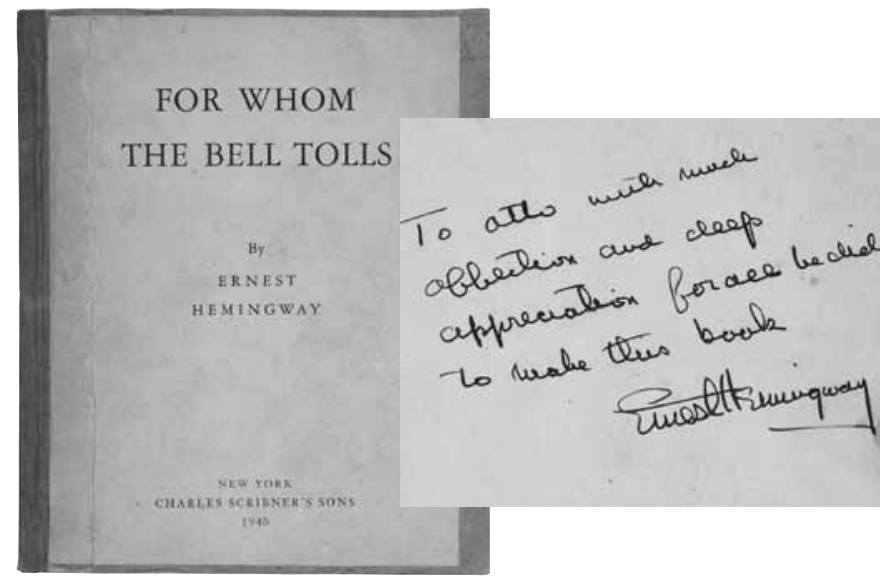

Ernest Hemingway, For Whom The Bell Tolls, NY, 1940. Advance proof signed and inscribed to Toby Otto Bruce. Estimate $\$ 75,000$ to $\$ 100,000$. At auction November 29.

\section{AUCTIONEERS \& APPRAISERS OF}

\section{RARE BOOKS • AUTOGRAPHS \& MANUSCRIPTS}

MAPS \& ATLASES • PHOTOGRAPHS

\section{PRINTS \& DRAWINGS • VINTAGE POSTERS}

We are proud to sell books, manuscripts and related material on behalf of:

The Adler Planetarium • The American Museum of Natural History

The Asia Society • Columbia University • The Grolier Club

The Hispanic Society of America • Kansas City Public Library

The Newberry Library • University of Chicago Library and many other fine collections.

Inquiries: Tobias Abeloff

tabeloff@swanngalleries.com·212 254 4710,ext 18 